\title{
Partial memory reinstatement while (lucid) dreaming to change the dream environment
}

\author{
Remington Mallett \\ Department of Psychology, University of Missouri at St. Louis, USA \\ Department of Psychology, University of Texas at Austin, USA (current address) \\ correspondence: \\ mallett.remy@gmail.com \\ 108 E Dean Keeton St, Austin, TX, 78712
}

\begin{abstract}
Lucid dreams often coincide with having control over dream events in real-time, although the limitations of dream control are not completely understood. The current study probed the ability of lucid dreamers to reinstate waking scene memories while dreaming. After brief exposure to an experimental scene, participants were asked to reinstate the scene while lucid dreaming (i.e., change dream scenery to match real-world scene). Qualitative analysis revealed that successful dream scene reinstatements were overwhelmingly inaccurate with respect to the original experimental scene. Importantly, reinstatement inaccuracies held even when the dreamer was aware of them during the dream, suggesting a dissociation between memory access while dreaming and dream imagery. The ability to change the environment of a dream speaks to the high amount of lucid dream control, yet the inaccuracies speak to a lack of detailed control. Reinstating context during lucid sleep offers an experimental method to investigate sleep, dreams, and memory.
\end{abstract}

\section{Keywords}

lucid dreams; dream control; episodic memory; memory retrieval; context reinstatement; sleep

\section{Significance statement}

Lucid dreaming has promising research, clinical, and recreational applications. All of these endeavors rely on the ability to control dream content, of which the limits are not completely understood. Here, lucid dreamers are able to change the dream scenery to mimic a real-world scene. When a real-world scene is reinstated as dream content, reinstatements show gross inaccuracies despite the dreamer being aware of the inaccuracies in real-time. This ability to change dream scenery - albeit with faults - offers insight and potential research avenues into sleep and memory. 


\section{Highlights}

- Participants can access waking episodic memories while lucid dreaming.

- Participants can manipulate the dream scene to mimic a real-world scene, albeit with demonstrable inaccuracies.

- Inaccurate dream reinstatements occur even when the dreamer is aware of the them while dreaming.

\section{Acknowledgements}

The author would like to thank Suzanne Welcome for mentorship, Emma Trammel for assistance and helpful discussion, and Kimber Mallett for contributing Figure 1.

\section{Funding statement}

This work was funded by a College of Arts \& Sciences Undergraduate Research Award from University of Missouri at St. Louis.

\section{Conflict of interest statement}

The author declares no conflict of interest.

\section{Resource availability statement}

All data, code, and materials are available on the OSF project site at https://osf.io/ndvj9.

\section{Word count}

Abstract -150

Body -6055 


\section{Introduction}

For the majority of dreams, we don't acknowledge the hallucinatory circumstance until we are awake and able to recall the experience. Dreams lack the reflective awareness that is required to acknowledge the hallucination while it is occurring (Nir \& Tononi, 2010). Without reflective awareness, we don't have volition - or conscious control - over the contents of the dream in real-time as we do while awake (Dresler et al., 2014). This inability to systematically control the content of dreams places a limitation on dream research.

A subset of dreams, known as lucid dreams, are those where the dreamer recognizes the dream state as it is occurring (Baird et al., 2019). Real-time recognition of the dream state often results in a similar realization that the dream is malleable, and that both the dreamer's body and the "perceptual" content of the dream can be manipulated according to the dreamer's intent (Stumbrys et al., 2014). Though lucid dreams involve more control on average than non-lucid dreams (Mota-Rolim et al., 2013; Voss et al., 2013), the direct relationship between lucidity and control is unclear (Aviram \& SofferDudek, 2018; Kahan, 1994). At home, lucid dreamers remember their waking intentions during only half of lucid dreams, and even if the intention is remembered they are often unable to complete the task due to "insufficient clarity" or "self-doubt" (among other reasons; Stumbrys et al., 2014). Another survey study found that the majority of participants report having control only "frequently" (4 on a 6-point scale) in lucid dreams (Mota-Rolim et al., 2013). Further, there are differing aspects of dream control (Lemyre et al., 2020), such as whether the dream body or the environment of the dream are being manipulated with volition (Schredl et al., 2018).

Bodily dream control was essential to the objective verification of lucid dreams (Hearne, 1978; LaBerge et al., 1981). To verify that someone could simultaneously show neurophysiological markers of sleep and be aware of the mental dream experience, participants were asked to send a predetermined signal from the dream that indicated their lucidity. During rapid eye movement (REM) sleep, muscles are generally paralyzed except for those of the eyes (Chase \& Morales, 1990). Utilizing this feature of REM sleep, participants were told before sleep that, upon dream lucidity, they should move their eyes in a systematic pattern during the dream (typically left-right-left-right). Upon completion of the task while dreaming, polysomnography shows both the systematic eye movements and global patterns consistent with a sleeping brain (see Baird et al., 2019 for review). Armed with the ability to control (i.e., experimentally manipulate) dream content, researchers have asked participants to complete a variety of tasks during their lucid dreams to better understand the dreaming brain (Erlacher \& Schredl, 2008b), ranging from clenching fists (Dresler et al., 2011; Erlacher et al., 2003) to exercising (Erlacher \& Schredl, 2008a), and even tickling themselves (Windt et al., 2014). These works suggest 
40 that the dream body is under explicit control during lucid control dreams, but what of the 41 dream environment itself?

42 George Gillespie, a prominent author of personal lucid dreaming experimentation, 43 reported that he would often attempt to "[change] the location of the dream" or plan in 44 advance "what the dream environment would be" (p. 325), though the success or 45 description of these accounts are not provided (Gillespie, 1988). In a similar vein, Alan Worsley reported success rates on a remarkable variety of personal experimentation on the limits of lucid dreaming, ranging from flying to generating sound, and even "limb lengthening" (Worsley, 1988). He noted success on a series of "television experiments" (p. 327) where he had explicit control over the content of a dreamed television or could "[tint] the whole visual field by the use of a color filter" (p. 337) on all of ten attempts. These reports hint at the possibility of changing dream scenery during lucid dreams. More quantitative approaches include a survey study where 107 of 517 respondents noted that they have set up waking intentions of "changing or observing dream events" during their lucid dreams (Stumbrys et al., 2014). Of the 107 intentions to change dream events, 44 were plans to change the "scene or perspective" of the dream and 33 were to change the "land(scape)." Importantly, it is unclear how many of these planned actions were executed (or even remembered) during the dream, since the same respondents reported that only about half of planned intentions were remembered and/or accomplished during dreaming. To "visit different places" was the most frequent activity performed during recreational lucid dreams, occurring in roughly half of all dreams in another survey study with 3427 respondents (Mota-Rolim et al., 2013). Another study found that half of participants who had experienced at least one lucid dream reported that they could "deliberately shape [their] environment" in lucid dreams, but only $5 \%$ of them reported this was the case in all their lucid dreams (Schredl et al., 2018). Kahan (1994) investigated different types of dream control across 239 home dream reports from 30 participants. The most frequently reported dream elements under control were the dreamer's own thoughts and feelings ( $72 \%$ and $64 \%$ of dreams, respectively). Elements under control with less frequency included the dream environment $(21 \%)$, as well as object characteristics $(17 \%)$, followed by object actions (12\%) and others' actions (11\%). Participants in the same study also self-reported lucidity levels, which were positively related to having control over the dream environment. How these dream environment changes occur are less clear. Though 72 without providing data, Tholey (1983) suggests that "experienced lucid dreamers

73 succeeded in altering a dream scenery simply by wishing it so" (p. 86) or by gazing at a 74 singular point in dream space for a limited amount of time. When asked explicitly to spin 75 the dream body as a method to alter lucid dream scenery, roughly half of 32 attempts 76 were reported as successful (Gackenbach \& LaBerge, 1989). An extensive content 77 analysis of dream control techniques also revealed the use of spinning to alter the dream 78 environment, though individual approaches varied, including the use of a door or portal, 
79 simply turning around, or "[crossing] a glass surface, a painting, or an opaque object to 80 transit to a new environment" (Lemyre et al., 2020).

The control that coincides with lucid dreaming is arguably its main attraction to research, clinical, and recreational applications (Appel et al., 2018). Thus, understanding 83 the limitations of controlling dream content is crucial to the development and progress of 84 all three endeavors. To investigate the limitations of dream control in the current study, participants were exposed to a scene in waking and asked to change their lucid dream environment to match the experimental scene (i.e., reinstate the scene while dreaming). Detailed dream reports indicated that (1) participants had the ability to change their dream environment to partially resemble the scene memory formed during waking, and (2) dream scene reinstatements included notable discrepancies from the real-world scenes. Interestingly, (3) the dream scene reinstatements were inaccurate even when the dreamer was aware of the inaccuracies while dreaming. The conscious access to waking memories and critical reflection of the inaccuracies while dreaming highlight the depth of cognition that can occur in lucid dreams. The ability to actively retrieve waking memories for the conscious manipulation of dream scenery, and the limitations of doing so, offer novel insight into dream control and provide a route to engineer the content of dreams.

\section{Methods}

99

\subsection{Participants}

Twenty-three participants (10 female, 13 male) participated in the current study. Advertisements for a lucid dreaming study were posted around the University of Missouri at St. Louis campus and surrounding regions. The study advertisement targeted "lucid dreamers," though there was no required lucid dreaming frequency. Ethics approval was provided through the University of Missouri at St. Louis Institutional Review Board.

\subsection{Procedure}

The general procedure was for participants to evaluate an experimental scene and then attempt to reinstate the scene while lucid dreaming at home (Figure 1). The task of dream scene reinstatement was to - during a lucid dream - "visit" the same experimental scene viewed during waking. Participants first completed a questionnaire about baseline dream characteristics/habits and a Lucidity and Consciousness in Dreams Scale (LuCiD; Voss et al., 2013) to evaluate certain lucidity-related factors in their "typical lucid dream experience" (i.e., trait lucidity). Questionnaires were followed by exposure to the experimental scene for $30-90$ seconds and a 16 -item memory test on its contents. The experimental scene was a physical room $(8 \times 8 \mathrm{ft})$, cleared except for two chairs, a desk with a computer, a shelf, and eight distinct stimuli that were selected for the experiment (Table 1). Participants were provided a packet to take home and instructed to attempt to 
119 explicitly recall the same scene during a lucid dream, actively investigate the environment, and report the experience in detail upon awakening. Participants completed a LuCiD scale upon awakening to evaluate state lucidity during the dream. Note that participants only completed dream reports for successful reinstatements, so failed dream scene reinstatements potentially occurred during the experiment but are not reported.
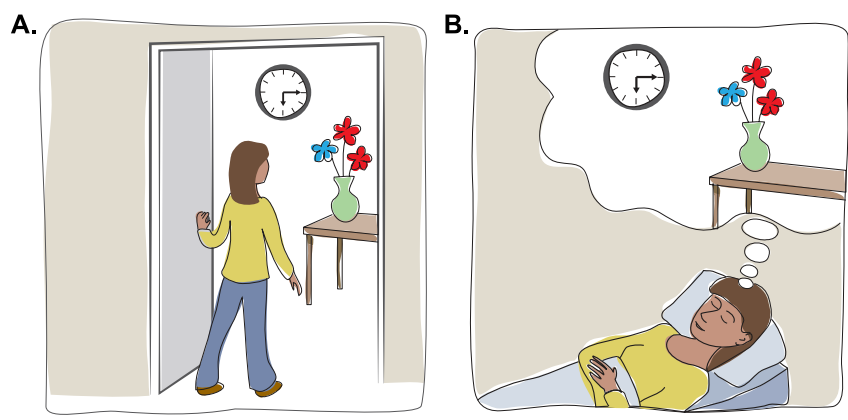

Figure 1. Participants (A) encoded an experimental scene/room and were asked to (B) lucid dream about the same scene and report the dream experience in detail.

Table 1. Experimental items placed in scene/room.

\begin{tabular}{l|l} 
Item & Brief description \\
\hline \hline Snake & Rubber rattlesnake in a coiled striking position \\
Fruit & Plastic fruit setup (pear, banana, etc.) \\
Picture of family & Mother, father, and son sitting around a chess board \\
Picture of individual & Headshot of female with striped (orange/blue) earrings and blue eyes \\
Artwork & Abstract digital painting made of many shapes \\
Clock & Round analog clock with Roman numerals set to 6:15 \\
Flowers & Six individual fake (realistic) roses of different colors \\
Blocks & Set of small toy blocks and shapes (one letter M), all red, blue, yellow, or green
\end{tabular}

\subsection{Measures and analyses}

The post-scene memory test had 2 free recall probes about a detail of each item (16 total probes). For example, "What time did the clock display?" was a probe about the clock. For each scene item, a participant is considered to have remembered the item if they got at least one of the two probes for that item correct, thus memory scores represent the proportion of the 8 items that were in memory after scene exposure.

Dream reports of successful reinstatements were evaluated qualitatively with a 132 thematic analysis (Braun \& Clarke, 2006). Individual reports were examined for any 133 memory-related themes, and then themes were judged for consistency across reports. 134 Themes are presented individually as subsections (of Section 3.2) with direct examples 135 from multiple dream reports as corroboration. 
For an exploratory analysis investigating the typical features of lucid dreams across the whole sample, the LuCiD scale was used to assess trait lucidity. To test for trait lucidity features, responses to the LuCiD scale probes were aggregated into their 8 pre-determined factors (Voss et al., 2013) for each participant. The LuCiD Likert scale response options range from 0 (Strongly disagree) to 5 (Strongly agree), so 2.5 was chosen as the neutral point which all factors were tested against using a 2-tailed Wilcoxon signed-rank test. State lucidity of successful dream reports are presented visually in the Appendix.

\section{Results}

\subsection{Lucid dreaming characteristics of sample and baseline memory}

All participants reported at least 2-4 lucid dreams per year (Figure 2A). Baseline lucid dreams contained positive emotions $(p<.001)$, control $(p<.001)$, thought $(p<.001)$, and insight $(p=.004$; Figure 2B). Notably, dissociation was not a descriptive feature of trait lucidity, and if anything trended as being less than neutral ( $p=.085$; cf., Voss et al., 2013). Average memory score for the entire sample was $0.8(S D=.21, \min =.4, \max =$ $1)$, and $.88(S D=.18, \min =.5, \max =1)$ for the lucid reinstatement group. Participantspecific memory scores are included alongside dream reports in the Appendix.

A.

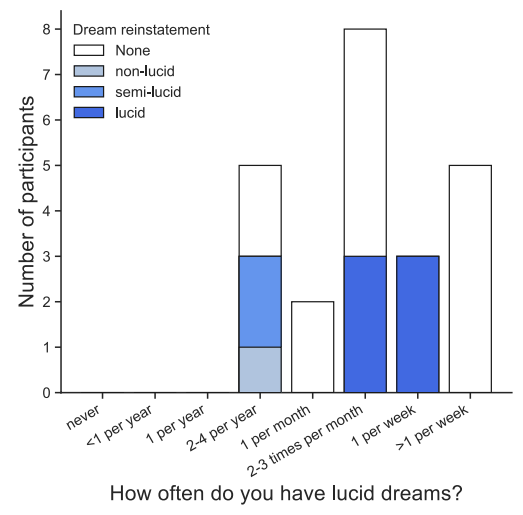

B.

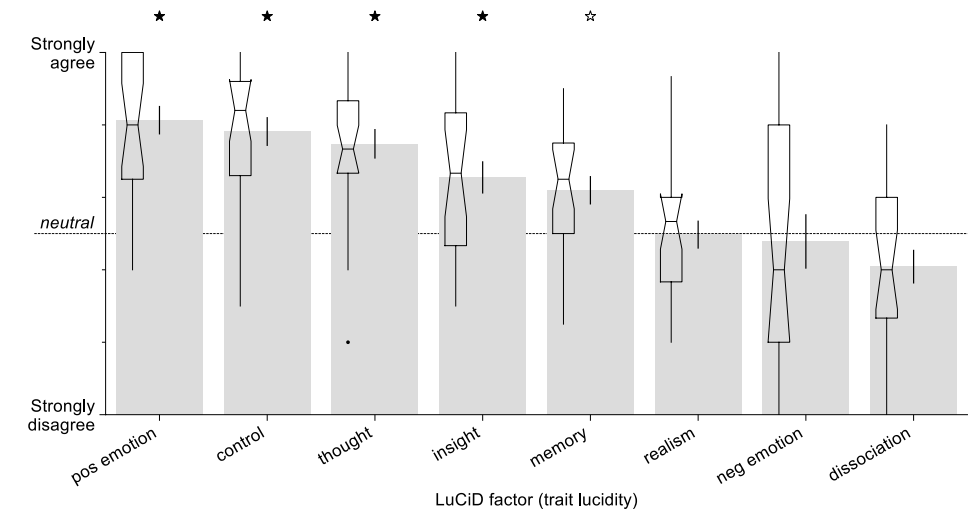

Figure 2. (A) Baseline lucid dreaming frequency of all participants and colors indicate the reinstatement task completion of each participant. (B) Trait LuCiD factors across all participants. Barplots represent mean and standard error, and boxplots represent median with lower and upper quartile range (notches indicate $95 \%$ confidence interval around the median and black circles indicate outliers). Stars indicate $p<.05$ and filled stars indicate $p<.006$ (Bonferroni-corrected alpha cutoff).

Nine of 23 participants reported successfully completing the task of reinstating the scene while dreaming, though 2 were from a semi-lucid dream and 1 was from a nonlucid dream (Figure 2A). Participants that reported completing the task while lucid tended 
161 to have higher lucid dreaming frequencies, reporting at least 2-3 lucid dreams per month. 162 Length of time between lab visit (i.e., scene exposure) and successful lucid dream 163 reinstatements varied between 0 and 70 days $(M=25, S D=28)$. Participant-specific 164 number of days between exposure and reinstatement are included alongside dream 165 reports in the Appendix. Notable consistencies across reports of lucid task completion were that (1) scene reinstatement occurred to a degree, (2) they were demonstrably imperfect, and (3) items were correctly recalled by the dreamer without being revealed in the content of the dream. Dream excerpts supporting each theme are presented below. All dream reports from successful reinstatements are included in the Appendix and abridged examples are presented in Table 2.

\subsubsection{Partial scene reinstatement is possible while dreaming}

Lucid participants had different strategies for reinstating the scene while dreaming (see also, Lemyre et al., 2020; Tholey, 1983). While some lucid participants were "just there" (sub-002), others used focused intention. For example, sub-009 recognized they were falling asleep and during the process actively "set the intention to go to the [experimental] room" and in doing so found themselves "going up the stairs that led to the [experimental] room." Another participant used pre-sleep focus during a meditation to "[envision] the room and [take] a walk through" before "falling asleep" (sub-010). One participant intentionally utilized their dream environment to reinstate the experimental scene; after a car appeared in their dream, they "used the car to fly to the university crashing into a window" and then "made [their] way into the correct area after navigating a maze of hallways" (sub-005).

\subsubsection{Dream scene reinstatements are imperfect}

The reinstatement of scenes while dreaming itself is notable, although such reinstatements were demonstrably imperfect. In most cases, the scenes started either empty or close to empty. Sub-005 "entered the room and it was mostly empty." Sub-007 "opened the door and the room was empty," but was able to populate the scene with specific items "as they were in the room" by "[closing their] eyes, [thinking] of an object that [they] could remember and [opening their] eyes and it would appear." One participant entered the scene after walking through the hallways of the original building, and noted that "walls were clean and table next to desk was not there. Also the big painting was not there, it was a plain white wall" (sub-009). Sub-010 "looked up at the clock to see what time it displayed, but there was nothing there."

When individual items were present, they were typically not exact reproductions of the real-world items. For example, while multiple scene reinstatements included the clock, it was never a precise replication of the clock from the experimental scene. Sub-005 reports "I remember the clock. It is there. When I focus on it I see Arabic numbers, though I thought at first it was Roman at first glance. The time six something... the minute hand 
201 is at the seven position but it's an eight. I focus and it changes to a seven for a second 202 but is trying to be eight." This example highlights how unstable lucid dreams can be (see 203 also, LaBerge \& DeGracia, 2000). Similarly, sub-005 notices that "[t]here is a picture 204 where the blonde one should be" and focuses to clear the image. In one instance, the 205 dreamer retains high levels of control despite a decaying background: "I saw the rattlesnake, it was mostly orange and black. The first time I saw the tail it had three black bands but when I looked again there were five, then seven and finally thirteen" (sub-009).

Sometimes items in the room were animated. After opening the dream door to an empty room, sub-007 "closed the door and tried to make things appear as they were in the room," but after making the clock appear, "[it] spun to midnight" and "[t]he digital painting was moving, and it was only squares." The snake - notably representative of something that is mobile in waking - was mobilized more in dreams than any other items. "The snake was real and moving across the floor" (sub-010) or "moved off the metal desk to the fruit and wrapped around them and then moved to the floor" (sub-007). In a similar vein, sometimes dream content was influenced by the scene items without being represented in their original form. Sub-002 reported that "[i]t is as if a giant pear-likeness is broadcast from the accurate pear location." Another participant "ended up in a park where the family from the photo was having a picnic [and] talked to them for a moment" (sub-010), although this was after losing lucidity.

While imperfect, there were notable cases of detailed item-level reinstatement while dreaming. After first entering the room, sub-009 noticed "the picture of the girl with green turquoise eyes and rainbow earrings, then moved forward to the desk" and came across the "geometrically shaped wooden figures mainly blue cylinders and letter R." While the actual letter was M, it's of interest that the blocks were even present in the scene, and especially that a single letter was present. Sub-007's dream contained the photo from the bookshelf, which is remarkable even if "the photo only had the chess game, not the family."

\subsubsection{Episodic memory access can be independent of dream content}

Participants reported being able to judge the accuracy of the reinstatement during the dream. Even though sub-005 "entered the room and it was mostly empty," they had enough access to the waking episodic scene memory that their first action was to "[recall] the items [they were] looking for and [note] missing elements, shelves, digital painting, desk gone, no end table." They proceed to note while dreaming that "[t]here is a picture where the blonde one should be." Sub-007 initially walked into the scene though it was void of all experimental items. With memory access to the waking scene, they began to populate the dream scene with the items: "... then I made the metal desk appear, and then the chair." Sub-010 reports that they "looked up at the clock to see what time it

239 displayed, but there was nothing there," and sub-007 noted awareness of the missing 240 table and painting in their dream report. 
Table 2. A subset of abridged lucid dream reinstatement reports. Text is bolded to highlight reports that are relevant to either the approach to reinstatement or the relevant themes. All unabridged reports are in the Appendix.

Participant Dream report

\begin{tabular}{l|ll}
\hline sub-005 & $\ldots$ I used the car to fly to the university crashing into a window. I made my way into
\end{tabular} the correct area after navigating a maze of hallways. I entered the [experimental] room to find it mostly empty. I recalled the items I was looking for and noted missing elements, shelves, digital painting, desk gone, no end table. There is a picture where the blonde one should be. It's blurry and watery ...

sub-007 $\quad \ldots$ I was wandering the halls of the building where the study took place ... this time they were full of ... shadowy figures ... I made it my mission to get to the room, but the closer I got the more crowded the hallways got ... but I reached my hand to the door ... the door was locked again ... so I imagined just passing through the door ... I opened the door and the room was empty ... I closed the door and tried to make things appear as they were in the room ... I would close my eyes, think of an object that I could remember and open my eyes and it would appear. First it was the wooden desk with the fruit ... I kept closing my eyes and trying to make it perfect, but then things got out of control. The clock above the switch spun to midnight ... the snake moved off the metal desk to the fruit and wrapped around them ...

sub-009 ... I caught myself in hypnagogia and set the intent to go to the [experimental] room. I then saw myself going up the northeast flight of stairs at [the university] ... turned left past the coffee mugs ... Went ahead into the [experimental] room. I saw the picture of the girl with green turquoise eyes and rainbow earrings, then moved forward to the desk. Looked down and around, walls were clean and table next to desk was not there. Also the big painting was not there, it was a plain white wall. I saw the rattlesnake, it was mostly orange and black. The first time I saw the tail it had three black bands but when I looked again there were five, then seven and finally thirteen ...

\section{Discussion}

The goal of the current study was to investigate the degree to which the lucid dream environment is malleable. Participants were briefly exposed to a scene during waking and asked to reinstate this scene during a lucid dream at home. Roughly one quarter of participants were able to reinstate the experimental scene during a lucid dream, wherein each case resulted in a dream environment that mimicked the scene with gross imperfections. These cases indicate that, in addition to bodily control, lucid dreams can involve partial control over dream scenery, including the ability to (imperfectly) reinstate specific real-world locations drawn from access to memories formed during waking. Of particular interest, the dream reinstatement inaccuracies held true even when participants were aware of them during the dream, highlighting a dissociation between memory access while dreaming and dream imagery. The current demonstration that lucid dreamers can self-initiate scenes and even specific items while dreaming, biasing the 
257 content of dreams towards a single context, might allow for useful studies towards uncovering the relationship between REM sleep, dreams, and memory.

\subsection{Relationship to non-lucid dreams: Are dreams episodic?}

Non-lucid dream content is at least partially dependent on previous experience (Nielsen \& Stenstrom, 2005; Schredl \& Hofmann, 2003; Vallat et al., 2017; van Rijn et al., 2015), yet strict episodic memory reinstatements rarely occur in non-lucid dreams (Baylor \& Cavallero, 2001; Dement et al., 1965; Fosse et al., 2003; Malinowski \& Horton, 2014; Nielsen \& Stenstrom, 2005; Stenstrom et al., 2012). Fosse et al. (2003) found that only $2 \%$ of dreams were comprised of episodic memory reinstatements, although they used a strict criterion for episodic memory; specifically a dream that included the precise location of the memory and that the location must be rated as "reasonably similar" to the waking version. Malinowski \& Horton (2014) used autonoetic consciousness as the only inclusion criterion for episodic dream content (see Gardiner, 2001 for theories relating autonoetic consciousness and episodic memory) and found only 1 of 186 dreams $(N=32)$ to fit this criteria. In a series of studies investigating the memory sources of dreams reviewed by Baylor \& Cavallero (2001), an external rating system was developed to quantify the amount of dreams containing "strict" episodic content, including "precise spatial and/or temporal coordinates" in relation to an episode of the participant's life (Cavallero, 1993). These studies found episodic dreams to be more prevalent from NREM than REM awakenings, although the amount of episodes was in general higher across all awakenings than related work, ranging from 28 to 55 percent. In a case study of NREM reports from an experienced dream reporter, Stenstrom et al. (2012) found only 1 "vaguely episodic" dream. In summary, despite minor discrepancies, the general consensus seems to be that episodic memories are rarely - if ever - fully replayed in non-lucid dreams. In the current study, when participants successfully reinstated the scene while dreaming, there was also a lack of high similarity with the original scene, suggesting that lucid dream content might share commonalities with non-lucid dream content (see also, Gackenbach, 1988). Thus, despite the ability to recall specific memories, there seems to be some inherent restriction that prevents dreams - lucid or not - from reconstructing precise memories in their entirety.

Memory replay during sleep confers benefits on subsequent waking memory (Klinzing et al., 2019). In human dream research, it is often presumed that dream content Stickgold, 2011). Based on the lack of episodic dream content in their study, Fosse et al. (2003) concluded that memory processing during REM sleep is not related to episodic memory. However, a lack of complete episodic reinstatement does not prevent episodic memory benefits from occurring, as dream contents might include pieces of an episodic memory (Plailly et al., 2019; Schwartz, 2003; Wamsley, 2014) or learning benefits of memory replay during sleep might be based on contextual memory replay (Boyce et al., 
2017). While episodic memory includes specific details of a time and place (Tulving, 2002), contextual memory is more generic (Smith \& Vela, 2001). The current dream reports of broadly successful scene reinstatements without accurate details supports the notion of contextual memory processing during REM sleep, although there is still much debate over any specific memory function of REM sleep (Genzel et al., 2015). Without proper polysomnography it is not clear whether the scene reinstatements of the current study occurred during REM, although the current view is that lucid dreams overwhelmingly occur during REM sleep (Baird et al., 2019).

\subsection{Dissociation between memory access while dreaming and dream imagery}

Successful dream scene reinstatement can be evaluated at two independent levels. First, did participants have the ability to access the episodic memory while dreaming? A dreamer has the capacity to recollect and perform mental imagery within the dream (Mallett, 2020; Worsley, 1988), and so the first step of recall while dreaming is to retrieve the memory, independent of changing dream content. Second, did the visual imagery/content of the dream mimic the episodic memory recollected by the dreamer? In the majority of lucid dream reinstatements presented here, only a minimal number of items from the real-world scene were accurately represented in dream imagery despite the dreamer being aware of the missing/incorrect items. This reported dissociation between episodic memory access while dreaming and dream imagery has implications for memory processing during dreams and dream control limitations.

By showcasing a lucid dreamer's ability to have episodic memory access that is not revealed in dream content, the present reports suggest that dream content might not necessarily be directly reflective of ongoing memory processing. The episodic memories accessed while lucid that were not reflected in dream content were nonetheless processed, though whether they can be deemed as "replay" is debatable. The real-time awareness of dream reinstatement inaccuracies also hints at possible limitations to dream control. At first glance, it seems that participants were unable to change dream scenery to precisely mimic the episodic memory. However, one participant (sub-007) reported that after an initial scene reinstatement with missing items, they were able to one-by-one insert the accurate items into the dream scene. Lucid dreaming frequency is positively related to dream control (Mota-Rolim et al., 2013; Stumbrys et al., 2014), and so it might be possible with lucid dreaming training to increase the accuracy of episodic dream scene reinstatement. One notoriously frequent lucid dreamer has observed that "fine detail [is] possible" in his own lucid dreams (p. 322, Worsley, 1988), although Tholey (1983) provides (also qualitative) reports that participants were never able to manipulate dream content to exactly match their desires. Notably, this dissociation between memory access and dream imagery was only observable with the real-time dream evaluation possible in lucid dreams, as the self-reflection required to access waking memories in real-time is not available in non-lucid dreams. 


\subsection{Lucid memory reactivation as a method to investigate sleep learning}

A lack of reliable dream manipulation methods has left the impact of dream content on memory processing tenuous (Plailly et al., 2019). Pre-sleep stimuli can influence dream content, although these effects are inconsistent and often influence only hypnagogic or non-REM dreams (Stickgold et al., 2000; Wamsley, Perry, et al., 2010; Wamsley, Tucker, et al., 2010), whereas the most content-rich dreams primarily occur in REM (Nielsen, 2000) and towards the end of the night (Chellappa \& Cajochen, 2013; Nielsen, 2004). Targeted Memory Reactivation, a recent method of biasing cognition and neural activity during sleep, has driven much of the current understanding of the relationship between non-REM sleep and memory (Creery et al., 2015; Oudiette \& Paller, 2013). Targeted Memory Reactivation works by forming paired associations during waking and replaying a stimulus during sleep to reactivate neural traces of a memory, but its impact on dream content is less clear. The method presented here - of using lucid dreamers to bias the dream scenery towards a particular context - might be utilized in future studies to bias dream content and quantify its impact on learning. An additional potential benefit of using lucid (as opposed to non-lucid) dreams for experimentation is the real-time metacognition of the task. As shown here, in lucid dreams the dreamer is able to consciously reflect on the true memory and accuracy of the dream reinstatement during the dream.

\subsection{Communicating lucidity requires waking memory retrieval}

The original description of lucid dreams included access to waking memories: "In these dreams the reintegration of the psychic functions is so complete that the sleeper remembers day-life" (p. 446, van Eeden, 1913). Though there were differing opinions about the inclusion of waking memory access in the definition of lucid dreams (Gillespie, 1983), the modern definition has been reduced to only the awareness of dreaming while dreaming (Baird et al., 2019). For the present experiment, and for most lucid dreaming experiments that require the completion of a specific task, the dream necessarily includes access to a waking memory. That is, most cases of task completion while lucid should start with the process of active retrieval (to recall the waking task). This should even be the case for the most basic task of specific eye movement patterns to verify lucidity, as in the case of "signal-verified lucid dreams" (SVLDs). SVLDs are the gold standard for objectively verifying lucidity during dreams, and thus are typically required of all participants when investigating the neural correlates of dream lucidity (e.g., Dresler et al., 2012; Voss et al., 2009). SVLDS are those where the dreaming participant (1) becomes lucid, (2) recalls the wake-formed memory to perform eye movements and in what order, (3) controls the dream body to execute those eye movements in the correct order, and (4) upon awakening reports that they were lucid and performed the task within the dream.

376 Completing this checklist requires both access to waking memory and dream control. 
377 These eye movements are also used to timestamp dream events for analysis, which 378 means that measuring lucidity around predetermined eye movements inherently includes 379 these other cognitive components. If lucidity is defined as only the awareness of a dream, 380 then it is important to consider these other factors when describing its neural and 381 phenomenological characteristics.

\subsection{Limitations}

A major limitation of the current study is its reliance on dream recall (Rosen, 2013), which, like waking recall, is a constructive and fallible process (Schacter et al., 1998). However, subjective reports are the most viable approach to evaluating dream content (Wamsley, 2013; Windt, 2013). The reliance on subjective reports could be overcome through the use of neural measures of objective task completion (e.g., Mallett, 2020). Given that the current dream reports include contextual scene reinstatement, applying neural decoding measures of context reinstatement (e.g., Bornstein \& Norman, 2017; Gershman et al., 2013) to this paradigm might be useful as another method to validate participant reports and quantify the relationship to waking memory. The similarity in neural resources recruited for dream and waking experiences (Dresler et al., 2011; Horikawa et al., 2013) highlights the plausibility of this approach. Additionally, novel approaches to real-time communication from a lucid dream (Appel, 2013; Mallett, 2020) might allow lucid dreamers to bypass the problem of dream recall and report the accuracy of their memory reinstatement in real-time.

A more parsimonious explanation for inaccurate dream scene reinstatements might be that the scene memory degraded over time between the lab visit and home dream reinstatement. Without a reliable measure of waking memory around the time of dream reinstatement this possibility can't be excluded, however it is unlikely for two reasons. First, visual long-term memory has a remarkably large and detailed capacity (Brady et al., 2008), including scenes (Konkle et al., 2010), and so the simple scene used in the current experiment is unlikely to have lost much detail. Second, the theme of episodic memory access while dreaming (Section 3.2.3) suggests that even when the memory was clearly accessible it was not always revealed in dream content. This latter point also suggests that participants were not providing particularly biased dream reports in order to "succeed" in the experiment (i.e., reporting higher dream accuracy than what actually occurred).

The current study is also limited by its qualitative nature. The choice to perform a thematic analysis rather than attempt to quantify the episodic nature of dreams in the current sample was based on a combination of related factors. First, only a small number of participants reported completing the reinstatement task during a lucid dream. There is already the common issue of inducing lucid dreams that frequently limits the sample size of related experiments (Stumbrys et al., 2012). The current design places a further restriction by requiring dream control, which only possibly - not necessarily - cooccurs 
417 with lucidity (Mota-Rolim et al., 2013; Stumbrys et al., 2014). Second, outside of neural 418 decoding methods (e.g., Horikawa et al., 2013), there are many difficulties in objectively 419 verifying the content of dreams (Rosen, 2013). Even after accepting the value of first420 person dream reports (Wamsley, 2013; Windt, 2013), quantifying memory accuracy within/of dreams adds a further complication. There is not a clear consensus as to what 422 constitutes an episodic dream, or especially an "accurate" scene reinstatement, which is highlighted by the variety of measures chosen across previous related research (reviewed in Section 4.1). Together, low sample size and measurement ambiguities make it difficult to provide accurate estimates of lucid dream reinstatement accuracy that might apply to the general population. Instead, the goal of the current study is to provide a descriptive account of what happens when a participant is asked to reinstate an episodic memory as their dream environment. Detailed lucid dream phenomenology is largely unexplored, which makes small samples and subjective reports valuable in determining dream control limitations (even if idiosyncratic; Worsley, 1988) and directions for future research. While the current account provides compelling descriptive evidence that applies to at least a subset of experienced lucid dreamers, none of the conclusions are definitive. More quantified approaches to evaluating the accuracy of dream scene reinstatements will, of course, be extremely valuable.

Despite lucid dreaming showing promise as an experimental approach, it is unclear how much lucid dreams can offer insight into non-lucid dreams (Vallat \& Ruby, 2019). The two have distinct neural profiles (Dresler et al., 2012; Voss et al., 2009), but their psychology overlaps at least partially (Gackenbach, 1988), and so more research comparing these states is warranted. For example, the proposed benefits of dream content on memory (Wamsley, 2014; Wamsley \& Stickgold, 2011) might rely on a certain level of spontaneity and/or unconscious access, such that a conscious and deliberate decision to recall a specific memory while lucid might not confer the same benefits. That is, any memory and/or emotional benefits of non-lucid dreaming might need to stay "unconscious" (see Buckley, 1988; Gackenbach, 1987; Sparrow, 2014) for related ethical concerns of dream control). Furthermore, recent opinion papers have noted that it is too early to tell whether lucid dreaming and/or its induction processes have any negative consequences on psychological health (Soffer-Dudek, 2020; Vallat \& Ruby, 2019; see also Dane, 1991).

\subsection{Conclusion}

The present study suggests that dream scenery can be intentionally manipulated to partially mimic real-world locations while lucid. When participants reinstated a waking memory as the dream environment their reinstatements were broadly imperfect, suggesting that dream imagery was manipulated to match a waking context rather than episode. Although dream imagery was only contextual, participants were aware of the reinstatement inaccuracies during the dream, indicating an access to episodic memory 
457 while dreaming that did not influence dream imagery. The dissociation between episodic 458 memory access while dreaming and contextual dream imagery highlights the cognitive 459 depths of lucidity and suggests that reinstatement accuracy might be improved with 460 lucidity training in the future. Reinstating specific waking scenes during lucid dreams 461 should be added to the existing repertoire of methods to engineer sleep and dream 462 content. 


\section{REFERENCES}

Appel, K. (2013). Communication with a sleeping person [Master's]. University of Osnabrück.

Appel, K., Pipa, G., \& Dresler, M. (2018). Investigating consciousness in the sleep laboratory - an interdisciplinary perspective on lucid dreaming. Interdisciplinary Science Reviews, 43(2), 192-207. https://doi.org/10.1080/03080188.2017.1380468

Aviram, L., \& Soffer-Dudek, N. (2018). Lucid Dreaming: Intensity, But Not Frequency, Is Inversely Related to Psychopathology. Frontiers in Psychology, 9. https://doi.org/10.3389/fpsyg.2018.00384

Baird, B., Mota-Rolim, S. A., \& Dresler, M. (2019). The cognitive neuroscience of lucid dreaming. Neuroscience \& Biobehavioral Reviews, 100, 305-323. https://doi.org/10.1016/j.neubiorev.2019.03.008

Baylor, G. W., \& Cavallero, C. (2001). Memory Sources Associated with REM and NREM Dream Reports Throughout the Night: A New Look at the Data. Sleep, 24(2), 165-170. https://doi.org/10.1093/sleep/24.2.165

Bornstein, A. M., \& Norman, K. A. (2017). Reinstated episodic context guides samplingbased decisions for reward. Nature Neuroscience, 20(7), 997. https://doi.org/10.1038/nn.4573

Boyce, R., Williams, S., \& Adamantidis, A. (2017). REM sleep and memory. Current Opinion in Neurobiology, 44, 167-177. https://doi.org/10.1016/j.conb.2017.05.001

Brady, T. F., Konkle, T., Alvarez, G. A., \& Oliva, A. (2008). Visual long-term memory has a massive storage capacity for object details. Proceedings of the National Academy of Sciences, 105(38), 14325-14329. https://doi.org/10.1073/pnas.0803390105

Braun, V., \& Clarke, V. (2006). Using thematic analysis in psychology. Qualitative Research in Psychology, 3(2), 77-101. https://doi.org/10.1191/1478088706qp063oa

Buckley, K. (1988). Lucid Dreaming and Ethical Reflection. Lucidity Letter, 7(1), Article 1. https://journals.macewan.ca/lucidity/article/view/792

Cavallero, C. (1993). The quest for dream sources. Journal of Sleep Research, 2(1), 13-16. https://doi.org/10.1111/j.1365-2869.1993.tb00054.x

Chase, M. H., \& Morales, F. R. (1990). The atonia and myoclonia of active (REM) sleep. Annual Review of Psychology, 41, 557-584. https://doi.org/10.1146/annurev.ps.41.020190.003013

Chellappa, S. L., \& Cajochen, C. (2013). Ultradian and circadian modulation of dream recall: EEG correlates and age effects. International Journal of Psychophysiology, 89(2), 165-170. https://doi.org/10.1016/j.ijpsycho.2013.03.006

Creery, J. D., Oudiette, D., Antony, J. W., \& Paller, K. A. (2015). Targeted Memory Reactivation during Sleep Depends on Prior Learning. Sleep, 38(5), 755-763. https://doi.org/10.5665/sleep.4670 
Dane, J. R. (1991). Ethical Issues for Applications of Lucid Dreaming: An Introduction. Lucidity Letter, 10(1/2), Article 1/2.

https://journals.macewan.ca/lucidity/article/view/476

Dement, W. C., Kahn, E., \& Roffwarg, H. P. (1965). The influence of the laboratory situation on the dreams of the experimental subject. Journal of Nervous and Mental Disease, 140(2), 119-131. https://doi.org/10.1097/00005053-19650200000002

Dresler, M., Eibl, L., Fischer, C. F., Wehrle, R., Spoormaker, V. I., Steiger, A., Czisch, M., \& Pawlowski, M. (2014). Volitional components of consciousness vary across wakefulness, dreaming and lucid dreaming. Frontiers in Psychology, 4. https://doi.org/10.3389/fpsyg.2013.00987

Dresler, M., Koch, S. P., Wehrle, R., Spoormaker, V. I., Holsboer, F., Steiger, A., Sämann, P. G., Obrig, H., \& Czisch, M. (2011). Dreamed Movement Elicits Activation in the Sensorimotor Cortex. Current Biology, 21(21), 1833-1837. https://doi.org/10.1016/j.cub.2011.09.029

Dresler, M., Wehrle, R., Spoormaker, V. I., Koch, S. P., Holsboer, F., Steiger, A., Obrig, H., Sämann, P. G., \& Czisch, M. (2012). Neural Correlates of Dream Lucidity Obtained from Contrasting Lucid versus Non-Lucid REM Sleep: A Combined EEG/fMRI Case Study. Sleep, 35(7), 1017-1020. https://doi.org/10.5665/sleep.1974

Erlacher, D., \& Schredl, M. (2008a). Cardiovascular responses to dreamed physical exercise during REM lucid dreaming. Dreaming, 18(2), 112-121. https://doi.org/10.1037/1053-0797.18.2.112

Erlacher, D., \& Schredl, M. (2008b). Do REM (lucid) dreamed and executed actions share the same neural substrate? International Journal of Dream Research, 714. https://doi.org/10.11588/ijodr.2008.1.20

Erlacher, D., Schredl, M., \& LaBerge, S. (2003). Motor area activation during dreamed hand clenching: A pilot study on EEG alpha band. Sleep and Hypnosis, 5(4), 182-187.

Fosse, M. J., Fosse, R., Hobson, J. A., \& Stickgold, R. J. (2003). Dreaming and Episodic Memory: A Functional Dissociation? Journal of Cognitive Neuroscience, 15(1), 1-9. https://doi.org/10.1162/089892903321107774

Gackenbach, J. (1987). Concerns with Lucidity Essay. Lucidity Letter, 6(2), Article 2. https://journals.macewan.ca/lucidity/article/view/760

Gackenbach, J. (1988). The Psychological Content of Lucid versus Nonlucid Dreams. In J. Gackenbach \& S. LaBerge (Eds.), Conscious Mind, Sleeping Brain: Perspectives on Lucid Dreaming (pp. 181-220). Springer New York. https://doi.org/10.1007/978-1-4757-0423-5_9

Gackenbach, J., \& LaBerge, S. (1989). What is Possible in a Lucid Dream? Results of the April, 1987 OMNI Experiment. Lucidity Letter, 8(2). https://journals.macewan.ca/lucidity/article/view/829/769

Gardiner, J. M. (2001). Episodic memory and autonoetic consciousness: A first-person approach. Philosophical Transactions of the Royal Society of London. Series B: Biological Sciences, 356(1413), 1351-1361. https://doi.org/10.1098/rstb.2001.0955 
Genzel, L., Spoormaker, V. I., Konrad, B. N., \& Dresler, M. (2015). The role of rapid eye movement sleep for amygdala-related memory processing. Neurobiology of Learning and Memory, 122, 110-121. https://doi.org/10.1016/j.nlm.2015.01.008

Gershman, S. J., Schapiro, A. C., Hupbach, A., \& Norman, K. A. (2013). Neural Context Reinstatement Predicts Memory Misattribution. Journal of Neuroscience, 33(20), 8590-8595. https://doi.org/10.1523/JNEUROSCl.0096-13.2013

Gillespie, G. (1983). Memory and Reason in Lucid Dreams: A Personal Observation. Lucidity Letter, 2(4). https://journals.macewan.ca/lucidity/article/view/613

Gillespie, G. (1988). Without a Guru: An Account of My Lucid Dreaming. In J. Gackenbach \& S. LaBerge (Eds.), Conscious Mind, Sleeping Brain: Perspectives on Lucid Dreaming (pp. 343-350). Springer New York. https://doi.org/10.1007/978-1-4757-0423-5_14

Hearne, K. M. (1978). Lucid dreams: An electro-physiological and psychological study [Ph.D.]. University of Liverpool.

Horikawa, T., Tamaki, M., Miyawaki, Y., \& Kamitani, Y. (2013). Neural Decoding of Visual Imagery During Sleep. Science, 340(6132), 639-642. https://doi.org/10.1126/science.1234330

Kahan, T. L. (1994). Measuring dream self-reflectiveness: A comparison of two approaches. Dreaming, 4(3), 177-193. https://doi.org/10.1037/h0094411

Klinzing, J. G., Niethard, N., \& Born, J. (2019). Mechanisms of systems memory consolidation during sleep. Nature Neuroscience, 1-13. https://doi.org/10.1038/s41593-019-0467-3

Konkle, T., Brady, T. F., Alvarez, G. A., \& Oliva, A. (2010). Scene Memory Is More Detailed Than You Think: The Role of Categories in Visual Long-Term Memory. Psychological Science, 21(11), 1551-1556. https://doi.org/10.1177/0956797610385359

LaBerge, S., \& DeGracia, D. J. (2000). Varieties of lucid dreaming experience. In R. G. Kunzendorf \& B. Wallace (Eds.), Individual Differences in Conscious Experience (pp. 269-307). John Benjamins Publishing.

LaBerge, S., Nagel, L. E., Dement, W. C., \& Zarcone, V. P. (1981). Lucid Dreaming Verified by Volitional Communication during Rem Sleep. Perceptual and Motor Skills, 52(3), 727-732. https://doi.org/10.2466/pms.1981.52.3.727

Lemyre, A., Légaré-Bergeron, L., Landry, R. B., Garon, D., \& Vallières, A. (2020). HighLevel Control in Lucid Dreams. Imagination, Cognition and Personality, 0276236620909544. https://doi.org/10.1177/0276236620909544

Malinowski, J. E., \& Horton, C. L. (2014). Memory sources of dreams: The incorporation of autobiographical rather than episodic experiences. Journal of Sleep Research, 23(4), 441-447. https://doi.org/10.1111/jsr.12134

Mallett, R. (2020). A pilot investigation into brain-computer interface use during a lucid dream. International Journal of Dream Research, 13(1), 62-69. https://doi.org/10.11588/ijodr.2020.1.68010

Mota-Rolim, S. A., Targino, Z. H., Souza, B. C., Blanco, W., Araujo, J. F., \& Ribeiro, S. (2013). Dream characteristics in a Brazilian sample: An online survey focusing on lucid dreaming. Frontiers in Human Neuroscience, 7.

https://doi.org/10.3389/fnhum.2013.00836 
Nielsen, T. A. (2000). A review of mentation in REM and NREM sleep: "Covert" REM sleep as a possible reconciliation of two opposing models. Behavioral and Brain Sciences, 23(6), 851-866. https://doi.org/10.1017/S0140525X0000399X

Nielsen, T. A. (2004). Chronobiological features of dream production. Sleep Medicine Reviews, 8(5), 403-424. https://doi.org/10.1016/j.smrv.2004.06.005

Nielsen, T. A., \& Stenstrom, P. (2005). What are the memory sources of dreaming? Nature, 437(7063), 1286. https://doi.org/10.1038/nature04288

Nir, Y., \& Tononi, G. (2010). Dreaming and the brain: From phenomenology to neurophysiology. Trends in Cognitive Sciences, 14(2), 88-100. https://doi.org/10.1016/j.tics.2009.12.001

Oudiette, D., \& Paller, K. A. (2013). Upgrading the sleeping brain with targeted memory reactivation. Trends in Cognitive Sciences, 17(3), 142-149. https://doi.org/10.1016/j.tics.2013.01.006

Plailly, J., Villalba, M., Vallat, R., Nicolas, A., \& Ruby, P. (2019). Incorporation of fragmented visuo-olfactory episodic memory into dreams and its association with memory performance. Scientific Reports, 9(1), 1-14. https://doi.org/10.1038/s41598-019-51497-y

Rosen, M. G. (2013). What I make up when I wake up: Anti-experience views and narrative fabrication of dreams. Frontiers in Psychology, 4. https://doi.org/10.3389/fpsyg.2013.00514

Schacter, D. L., Norman, K. A., \& Koutstaal, W. (1998). The Cognitive Neuroscience of Constructive Memory. Annual Review of Psychology, 49(1), 289-318. https://doi.org/10.1146/annurev.psych.49.1.289

Schredl, M., \& Hofmann, F. (2003). Continuity between waking activities and dream activities. Consciousness and Cognition, 12(2), 298-308. https://doi.org/10.1016/S1053-8100(02)00072-7

Schredl, M., Rieger, J., \& Göritz, A. S. (2018). Measuring lucid dreaming skills: A new questionnaire (LUSK). International Journal of Dream Research, 11(1), 54-61. https://doi.org/10.11588/ijodr.2018.1.44040

Schwartz, S. (2003). Are life episodes replayed during dreaming? Trends in Cognitive Sciences, 7(8), 325-327. https://doi.org/10.1016/S1364-6613(03)00162-1

Smith, S. M., \& Vela, E. (2001). Environmental context-dependent memory: A review and meta-analysis. Psychonomic Bulletin \& Review, 8(2), 203-220. https://doi.org/10.3758/BF03196157

Soffer-Dudek, N. (2020). Are Lucid Dreams Good for Us? Are We Asking the Right Question? A Call for Caution in Lucid Dream Research. Frontiers in Neuroscience, 13. https://doi.org/10.3389/fnins.2019.01423

Sparrow, G. S. (2014). A non-dual perspective on the question of dream control. In Lucid Dreaming: New Perspectives on Consciousness in Sleep (Vol. 1, pp. 325346). Praeger.

Stenstrom, P., Fox, K., Solomonova, E., \& Nielsen, T. (2012). Mentation during sleep onset theta bursts in a trained participant: A role for NREM stage 1 sleep in memory processing? International Journal of Dream Research, 5(1), 37-46.

Stickgold, R., Hobson, J. A., Fosse, R., \& Fosse, M. (2001). Sleep, Learning, and Dreams: Off-line Memory Reprocessing. Science, 294(5544), 1052-1057. https://doi.org/10.1126/science.1063530 
Stickgold, R., Malia, A., Maguire, D., Roddenberry, D., \& O'Connor, M. (2000). Replaying the Game: Hypnagogic Images in Normals and Amnesics. Science, 290(5490), 350-353. https://doi.org/10.1126/science.290.5490.350

Stumbrys, T., Erlacher, D., Johnson, M., \& Schredl, M. (2014). The Phenomenology of Lucid Dreaming: An Online Survey. The American Journal of Psychology, 127(2), 191-204. JSTOR.

Stumbrys, T., Erlacher, D., Schädlich, M., \& Schredl, M. (2012). Induction of lucid dreams: A systematic review of evidence. Consciousness and Cognition, 21(3), 1456-1475. https://doi.org/10.1016/j.concog.2012.07.003

Tholey, P. (1983). Techniques for Inducing and Manipulating Lucid Dreams. Perceptual and Motor Skills, 57(1), 79-90. https://doi.org/10.2466/pms.1983.57.1.79

Tulving, E. (2002). Episodic Memory: From Mind to Brain. Annual Review of Psychology, 53(1), 1-25. https://doi.org/10.1146/annurev.psych.53.100901.135114

Vallat, R., Chatard, B., Blagrove, M., \& Ruby, P. (2017). Characteristics of the memory sources of dreams: A new version of the content-matching paradigm to take mundane and remote memories into account. PLOS ONE, 12(10), e0185262. https://doi.org/10.1371/journal.pone.0185262

Vallat, R., \& Ruby, P. M. (2019). Is It a Good Idea to Cultivate Lucid Dreaming? Frontiers in Psychology, 10. https://doi.org/10.3389/fpsyg.2019.02585

van Eeden, F. (1913). A study of dreams. Proceedings of the Society for Psychical Research, 26, 431-461.

van Rijn, E., Eichenlaub, J. B., Lewis, P. A., Walker, M. P., Gaskell, M. G., Malinowski, J. E., \& Blagrove, M. (2015). The dream-lag effect: Selective processing of personally significant events during Rapid Eye Movement sleep, but not during Slow Wave Sleep. Neurobiology of Learning and Memory, 122, 98-109. https://doi.org/10.1016/j.nIm.2015.01.009

Voss, U., Holzmann, R., Tuin, I., \& Hobson, A. J. (2009). Lucid Dreaming: A State of Consciousness with Features of Both Waking and Non-Lucid Dreaming. Sleep, 32(9), 1191-1200. https://doi.org/10.1093/sleep/32.9.1191

Voss, U., Schermelleh-Engel, K., Windt, J., Frenzel, C., \& Hobson, A. (2013). Measuring consciousness in dreams: The lucidity and consciousness in dreams scale. Consciousness and Cognition, 22(1), 8-21. https://doi.org/10.1016/j.concog.2012.11.001

Wamsley, E. J. (2013). Dreaming, waking conscious experience, and the resting brain: Report of subjective experience as a tool in the cognitive neurosciences. Frontiers in Psychology, 4. https://doi.org/10.3389/fpsyg.2013.00637

Wamsley, E. J. (2014). Dreaming and Offline Memory Consolidation. Current Neurology and Neuroscience Reports, 14(3), 433. https://doi.org/10.1007/s11910-013-04335

Wamsley, E. J., Perry, K., Djonlagic, I., Reaven, L. B., \& Stickgold, R. (2010). Cognitive Replay of Visuomotor Learning at Sleep Onset: Temporal Dynamics and Relationship to Task Performance. Sleep, 33(1), 59-68. https://doi.org/10.1093/sleep/33.1.59 
Wamsley, E. J., \& Stickgold, R. (2011). Memory, Sleep, and Dreaming: Experiencing Consolidation. Sleep Medicine Clinics, 6(1), 97-108. https://doi.org/10.1016/j.jsmc.2010.12.008

Wamsley, E. J., Tucker, M., Payne, J. D., Benavides, J. A., \& Stickgold, R. (2010). Dreaming of a Learning Task Is Associated with Enhanced Sleep-Dependent Memory Consolidation. Current Biology, 20(9), 850-855. https://doi.org/10.1016/j.cub.2010.03.027

Windt, J. M. (2013). Reporting dream experience: Why (not) to be skeptical about dream reports. Frontiers in Human Neuroscience, 7. https://doi.org/10.3389/fnhum.2013.00708

Windt, J. M., Harkness, D. L., \& Lenggenhager, B. (2014). Tickle me, I think I might be dreaming! Sensory attenuation, self-other distinction, and predictive processing in lucid dreams. Frontiers in Human Neuroscience, 8. https://doi.org/10.3389/fnhum.2014.00717

Worsley, A. (1988). Personal Experiences in Lucid Dreaming. In J. Gackenbach \& S. LaBerge (Eds.), Conscious Mind, Sleeping Brain: Perspectives on Lucid Dreaming (pp. 321-341). Springer New York. https://doi.org/10.1007/978-1-47570423-5_13 


\section{APPENDIX}

Note: These reports make reference to a "red room", which was the physical room participants viewed in-person and were asked to visit during a lucid dream. The reports also make reference to a "blue room", which participants also viewed in-person but was involved in a separate experiment and is not discussed in the current manuscript.

\section{Lucid reinstatement reports}

\section{sub-004}

\section{Were you lucid in this dream?}

Yes.

\section{Describe your dream.}

I had been dreaming about fooling around with my ex-boyfriend on my parents' couch in the house where I grew up. Then I thought "oh, before you get up, visit the dream room." Red room. In the vestibular room I'm looking from approximately where [the researcher] stood, by the edge of the counter. An anime-style avatar in the form of a cute white girl with curly brown hair and a brown small, button-latched knapsack does a backflip from non-appearance to being true, before the door. Now looking at it head-on, it opens, slowly though, like a walk-in freezer's. Before I can look around, a kind of flashlight beam/spotlight shoots up on the opposite wall and shows the pear, yellowgreenish with a patch of rouge. It is as if a giant pear-likeness is broadcast from the accurate pear location, stage right upon the table but - oh - imagined in a bowl. At any rate the pear rotates rapidly through various orientations. A gridded, GPS info-bubble that pops up beside it says: "Your pear is here."

Were there elements of the dream that you could tell were not from the room? If so, what were they? Were they recognizable items from your past? Yes, I imagined the fruit in a bowl (silver, with a lip). I use these kinds of bowls at work for making salads and collecting avocados.

How did you get to the experimental environment in your dream? I was just there. A character, who seems to be sort of narratively responsible for the opening of the door, also appeared - backflip materializing out of dream thinair.

\section{How long were you in the environment?}

A few seconds.

Did you physically move in the environment, or just look around?

The environment didn't seem to have space/depth/detail to it. It was an idea of a room from the real room of the vestibule. 
Did you interact with the environment in any way (e.g., pick up objects)? No, not really. Though I have an auditory memory of the latch-sound that the refrigerator door in the basement where I work makes when the dream door (red door) opened.

Memory score: 1.0

Days between exposure and reinstatement: 0

Trait and state lucidity:

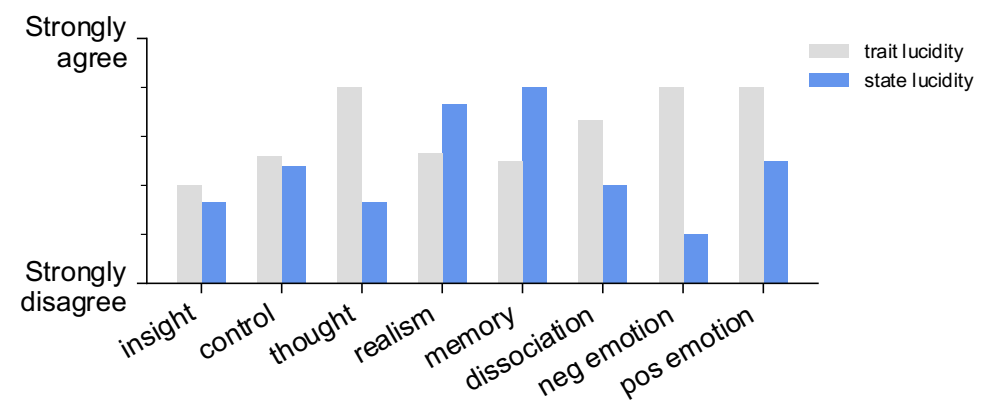

sub-005

Were you lucid in this dream?

Yes.

Describe your dream.

I "woke up" in a childhood home. Went outside and saw a co-worker in a car on the street. I used the car to fly to the university crashing into a window. I made my way into the correct area after navigating a maze of hallways. I entered the red room to find it mostly empty. I recalled the items I was looking for and noted missing elements, shelves, digital painting, desk gone, no end table. There is a picture where the blonde one should be. It's blurry and watery. I focus. When it clears, I see a black man in a blue graduation gown. He's holding both hands in the air in excitement. A rolled up diploma in his right hand. Face is really blurry. I remember the clock. It is there. When I focus on it I see Arabic numbers, though I thought at first it was Roman at first glance. The time six something... the minute hand is at the seven position but it's an eight. I focus and it changes to a seven for a second but is trying to be eight. I can't think what time this makes and the seven/eight morphing number confuses me. I decide to figure the time when I wake up and move to the blue room.

Were there elements of the dream that you could tell were not from the room? If so, what were they? Were they recognizable items from your past? Yes. The graduate. The gown was the same color as my high school graduation gown. It may be meaningless as blue is a common color in my dreams. The man was unknown to me. 
How did you get to the experimental environment in your dream? A flying car. I used expectation to make the building appear quickly.

How long were you in the environment?

That's hard to guess. Maybe ten minutes total dream time. Maybe two minutes in the room.

Did you physically move in the environment, or just look around? I moved.

Did you interact with the environment in any way (e.g., pick up objects)? Not in the red room.

Memory score: 0.875

Days between exposure and reinstatement: 2

Trait and state lucidity:

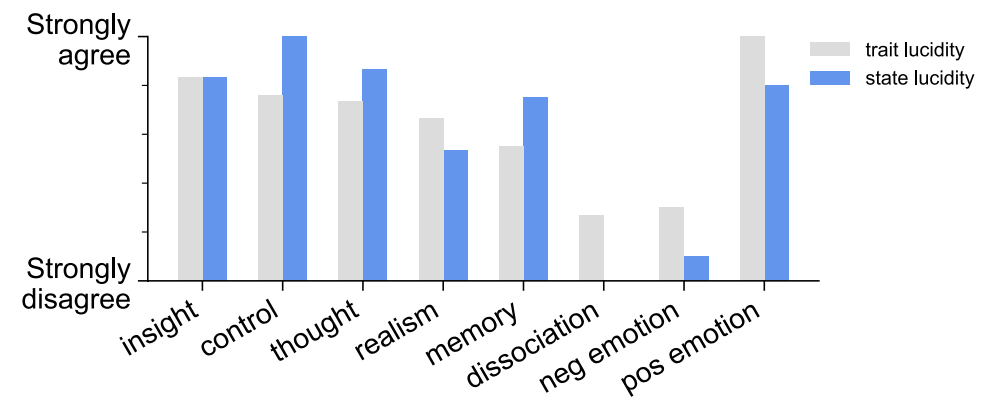

sub-007

Were you lucid in this dream?

Yes.

\section{Describe your dream.}

This dream came to me in a similar way to the one that I had about the blue room. I was wandering the halls of the building where the study took place. This time was much different though... The halls last time were completely empty and this time they were full of shadows. They were darkened, shadowy figures resembling people and I couldn't get them to go away. Regardless, I made it my mission to get to the room, but the closer I got the more crowded the hallways got and the louder the mumbles got from the shadows. As I could see the room, I got surrounded and my vision faded to darkness, but I reached my hand to the door, touched the knob and the hallways became empty once again. Of course the door was locked again, but I figured I should try to do something supernatural, so I imagined just passing through the door, and next thing I knew I 
was staring at the red door. I opened the door and the room was empty. I was still very lucid, so I closed the door and tried to make things appear as they were in the room. I soon realized that I couldn't do it with my eyes open, so I would close my eyes, think of an object that I could remember and open my eyes and it would appear. First it was the wooden desk with the fruit (no fruit yet), then I made the metal desk appear, and then the chair. I got a little distracted with details with the light switch / dimmer switch. I kept closing my eyes and trying to make it perfect, but then things got out of control. The clock above the switch spun to midnight and I quickly turned around. The digital painting was moving, and it was only squares, the snake moved off the metal desk to the fruit and wrapped around them and then moved to the floor by my feet. It then moved to the book shelf and disappeared behind the photo, but the photo only had the chess game, not the family. After that everything got blurry and I woke up shortly after.

Were there elements of the dream that you could tell were not from the room? If so, what were they? Were they recognizable items from your past? The shadows in the hallways. But the things in the room seemed to match up with the correct items, though the details were different.

How did you get to the experimental environment in your dream? Walked through halls to the room.

How long were you in the environment? Maybe a couple of minutes.

Did you physically move in the environment, or just look around? In the room I just looked around, but moved to get there.

Did you interact with the environment in any way (e.g., pick up objects)? Opened the door, but other than that, no.

Memory score: 1.0

Days between exposure and reinstatement: 70

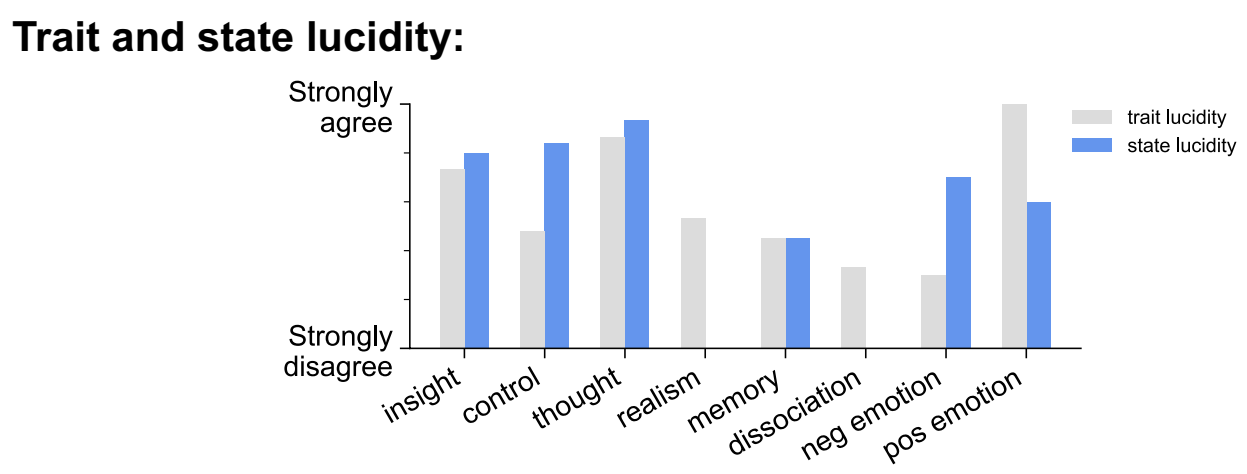


sub-009

Were you lucid in this dream?

Yes.

Describe your dream.

As I was flying back from [location] back to [location], I was falling asleep on the plane. I caught myself in hypnagogia and set the intent to go to the red room. I then saw myself going up the northeast flight of stairs at Stadler Hall [of the university]. That led to the third floor hallway, turned left passed the coffee mugs and the water fountain into the room where both red and blue doors are located. Went ahead into red room. I saw the picture of the girl with green turquoise eyes and rainbow earrings, then moved forward to the desk. Looked down and around, walls were clean and table next to desk was not there. Also the big painting was not there, it was a plain white wall. I saw the rattlesnake, it was mostly orange and black. The first time I saw the tail it had three black bands but when I looked again there were five, then seven and finally thirteen. At the time it made sense so I moved towards the shelf on opposite side. Picture of family was still there, they were hugging and they were black. Also by the snake the roses were in the wooden pencil holder with six red and one blue roses. On the shelf some geometrically shaped wooden figures mainly blue cylinders and letter $R$ in red come to mind but didn't when filling the previous questions. I started losing lucidity but before it was gone I walked out and went into blue room. Blue room was way more fuzzy, but saw many things I couldn't recall at first. Details on the blue room post-dream packet.

Were there elements of the dream that you could tell were not from the room? If so, what were they? Were they recognizable items from your past? No, in the red room elements were missing, nothing new.

How did you get to the experimental environment in your dream?

As I set the intention I saw myself going up the stairs that led to the red room.

How long were you in the environment?

Not long almost in and out.

Did you physically move in the environment, or just look around? Physically moved and held stuff.

Did you interact with the environment in any way (e.g., pick up objects)? Yes lifted the rattlesnake to check bands.

Memory score: 0.75

Days between exposure and reinstatement: 13 


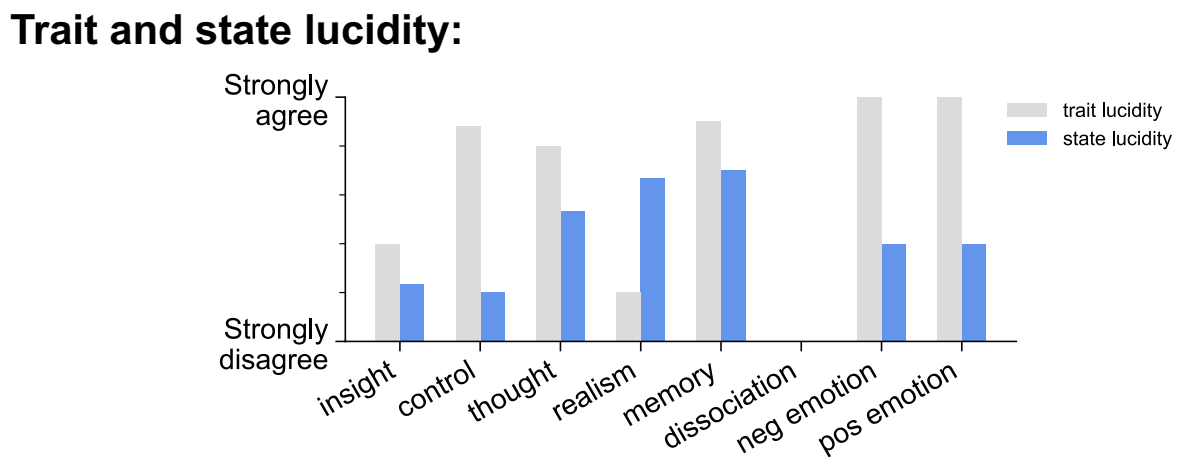

sub-010

Were you lucid in this dream?

At points.

Describe your dream.

This began as a meditation, envisioning the room and taking a walk through. I tried to account for all the items. At some point, I fell into sleep but did not successfully WILD. The room was still present. The snake was real and moving across the floor. I was not afraid. I looked up at the clock to see what time it displayed, but there was nothing there. For a moment, I said out loud that I was dreaming but I think I lost awareness of that pretty quick. I ended up in a park where the family from the photo was having a picnic, I talked to them for a moment but I can't recall what we talked about. At that point, I woke up and can't remember anything else.

Were there elements of the dream that you could tell were not from the room? If so, what were they? Were they recognizable items from your past? Yes, being outside with the family. It was the family from the photo, I talked to them.

How did you get to the experimental environment in your dream? I began with meditation and fell into sleep.

How long were you in the environment? It seemed to only be minutes.

Did you physically move in the environment, or just look around? I moved around, walking then just appeared in the park.

Did you interact with the environment in any way (e.g., pick up objects)? Talked to the family.

Memory score: 0.875 
Days between exposure and reinstatement: 46

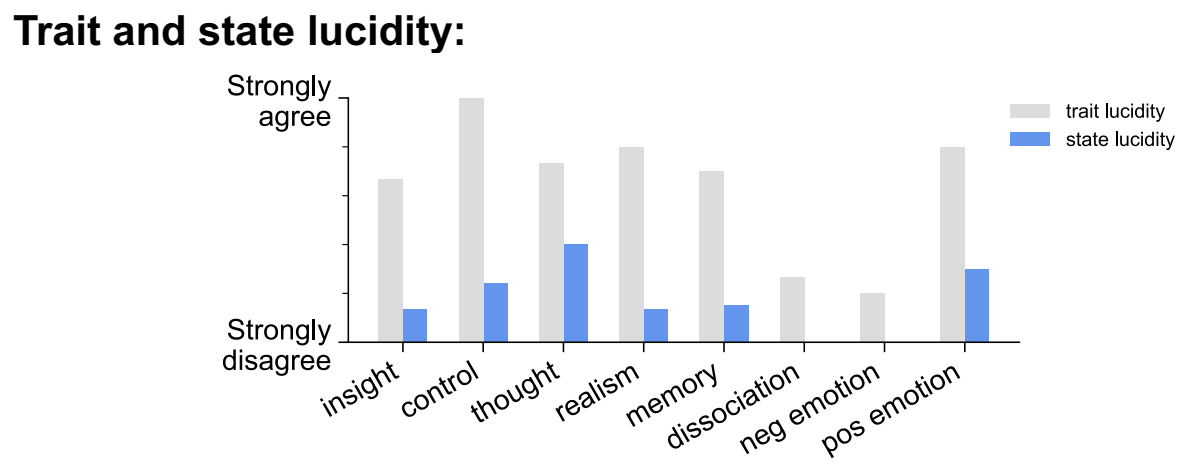

sub-022

Were you lucid in this dream?

Yes.

Describe your dream.

I walked back into the room and looked around.

Were there elements of the dream that you could tell were not from the room? If so, what were they? Were they recognizable items from your past? No.

How did you get to the experimental environment in your dream?

(?) I concentrated on it.

How long were you in the environment?

A few minutes at most.

Did you physically move in the environment, or just look around? I did move, and looked around as well.

Did you interact with the environment in any way (e.g., pick up objects)? No.

Memory score: 0.5

Days between exposure and reinstatement: 18

Trait and state lucidity: 


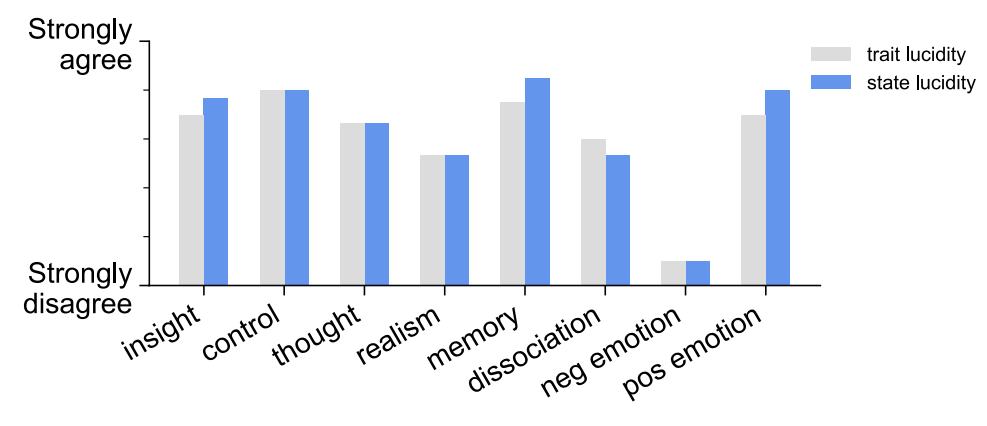

Semi-lucid reinstatement reports

sub-002

Were you lucid in this dream?

Barely/briefly.

Describe your dream.

I opened the door of the red room and saw that it was occupied by a sloth-like creature with the face of a woman. It was sliding slowly across the floor, reaching for a piece of paper stuck under a desk leg. I was fascinated by the creature's presence and movement. Its eyes were locked with mine. I knew it was too strange to be real, but did not fully comprehend that I was in a dream.

Were there elements of the dream that you could tell were not from the room? If so, what were they? Were they recognizable items from your past? Yes. The sloth-like creature. I had seen a video clip of a sloth recently.

How did you get to the experimental environment in your dream? Visualization.

How long were you in the environment?

Two minutes (?)

Did you physically move in the environment, or just look around? Moved through doorway.

Did you interact with the environment in any way (e.g., pick up objects)? Eye contact with sloth.

Memory score: 1.0

Days between exposure and reinstatement: 3

Trait and state lucidity: 


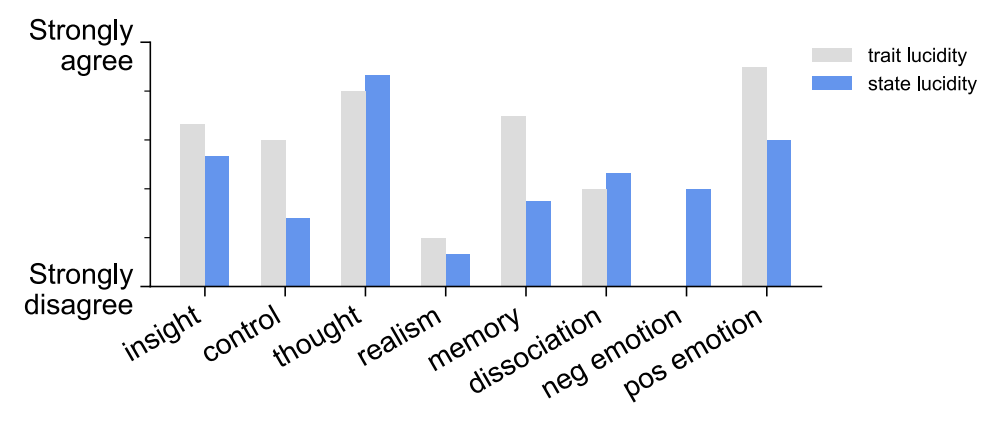

sub-012

Were you lucid in the dream?

I think so.

Describe your dream.

It felt more like astral projection. I had just gone back to bed and could feel my body humming, whirring, and vibrating. I tried to separate but it didn't exactly happen the way that I have experienced it before. But I could see things in my mind somehow. I just tried to remember what to search for, focused on each object one-at-a-time, and then when I stopped focusing on the room I returned to a more normal state.

Were there elements of the dream that you could tell were not from the room? If so, what were they? Were they recognizable items from your past? Not for sure - but I don't know if things were the same as in real life. I only saw the things I was looking for.

How did you get to the experimental environment in your dream? Going back to bed, laying on my back, focusing intently on the red door.

How long were you in the environment?

A few minutes?

Did you physically move in the environment, or just look around? It wasn't exactly either. It was kind of like I was just focusing very intently on one thing at a time.

Did you interact with the environment in any way (e.g., pick up objects)? No, just visualized.

Memory score: 0.75

Days between exposure and reinstatement: 12

Trait and state lucidity: 


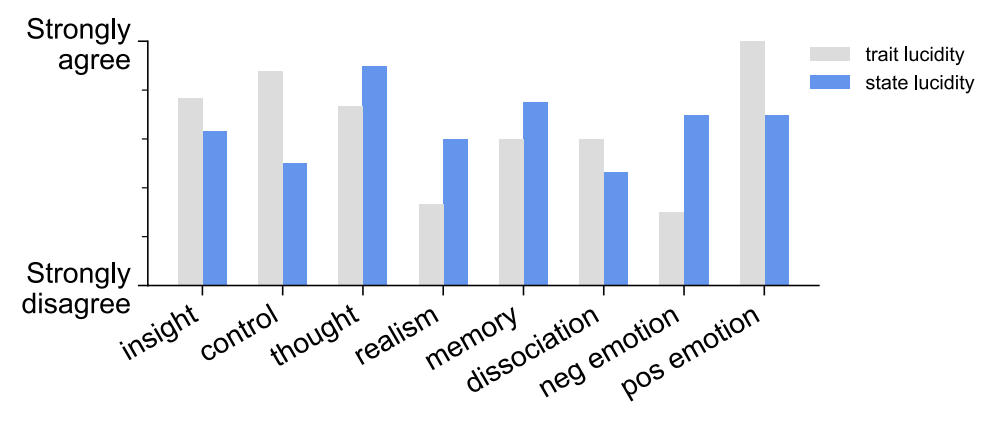

Non-lucid reinstatement reports

sub-014

Were you lucid in this dream?

No.

Describe your dream.

I remember talking to someone in the room. I don't remember much, as I only remember after waking up that I was in the room. I was facing the back wall with the digital painting on it, but the wall was blank, the artwork was gone. I saw the cinder block bricks that were painted with a glossy gray color. The lighting in the room was darker than I remembered it being. I had a faint impression that there was a white metal cabinet to my left and a desk to my right, but don't know if my waking memories mixed with my recollection of the room in the dream. I can't be sure which of the two rooms I was in other than a vague sense of "knowing" it was the red room instead of the blue room. I was dreaming in another locale that ended in the red room. I can't remember who I was talking to, but he was not from the experiment, it was from another part of the dream sequence.

Were there elements of the dream that you could tell were not from the room? If so, what were they? Were they recognizable items from your past? The person I was with was not related to the experiment. The painting was gone. The cabinet could be from my own garage (I have a cabinet like that in there). The lighting was dim.

How did you get to the experimental environment in your dream? Don't recall. I was in another house in my dream and ended the dream in the experiment room.

How long were you in the environment?

Hard to judge. My impression was that it was less than a minute or two.

Did you physically move in the environment, or just look around? No, I was facing the wall and talking to someone at my side. 
Did you interact with the environment in any way (e.g., pick up objects)? No.

Memory score: 0.875

Days between exposure and reinstatement: 4

Trait and state lucidity:

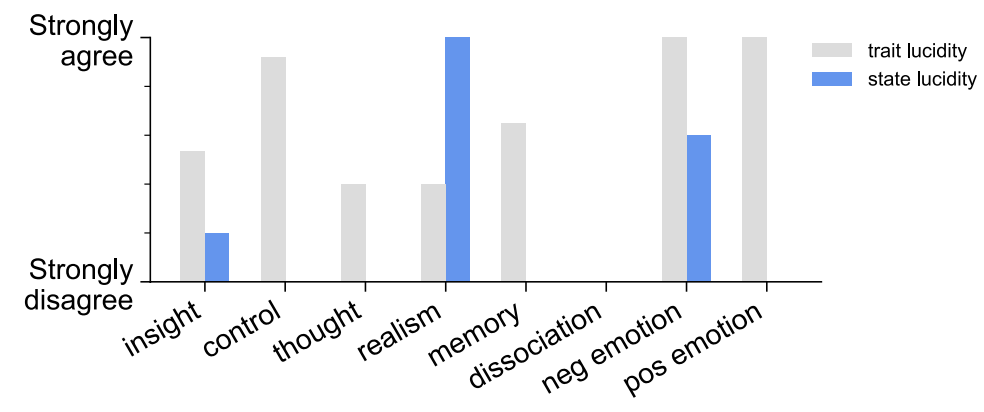

